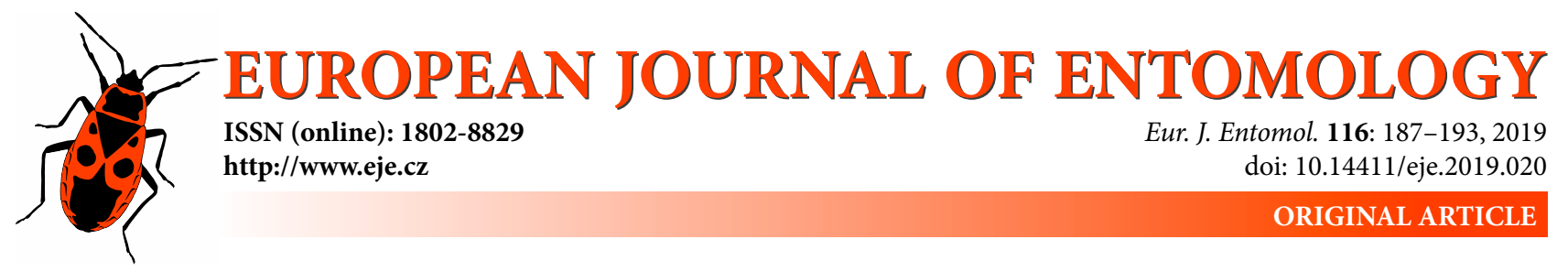

\title{
Mating activity of Pyrrhocoris apterus (Heteroptera: Pyrrhocoridae) in nature
}

\author{
AloIs HONĚK ${ }^{1}$, ZdenKa MARTINKOVÁ ${ }^{1}$ and MAREK BRABEC ${ }^{2}$ \\ ${ }^{1}$ Crop Research Institute, Drnovska 507, 16106 Praha 6 - Ruzyne, Czech Republic; e-mails: honek@vurv.cz, \\ martinkova@vurv.cz \\ ${ }^{2}$ Department of Statistical Modeling, Institute of Computer Sciences AS CR, Pod Vodarenskou vezi 271/2, \\ 18207 Praha 8, Czech Republic; e-mail: mbrabec@cs.cas.cz
}

Key words. Heteroptera, Pyrrhocoridae, Pyrrhocoris apterus, firebug, behaviour, copulation, daily changes, seasonal changes, sperm depletion

\begin{abstract}
The mating behaviour of Pyrrhocoris apterus in the laboratory is well studied, but little is known about it under natural conditions. In natural populations in Central Europe, overwintered adults start copulating in March and continue until their death. Caged females, kept under natural conditions in the permanent presence of males, copulated repeatedly. Their mating activity increased sharply until early April, then very slowly until the end of June and then declined as the females die-off. Half of copulations were short $(<5 \mathrm{~h})$ and only $9 \%$ were longer than 1 day. By contrast, in natural populations, mating activity (percentage of individuals involved in copula) reached its maximum in April and then decreased until early July, when the overwintered adults die. The decline in mating frequency (percentage of adults involved in copula) was associated with a decrease in the availability of receptive females towards the end of the mating period. For a female, repeated copulation is necessary because sperm is nearly depleted after insemination of 3-5 egg batches.
\end{abstract}

\section{INTRODUCTION}

Pyrrhocoris apterus L. is a West Palearctic species that has been intensively studied for a long time (Socha, 1993). Because of its abundance, overt mode of life, convenient size, easy rearing and handling, fast development and plastic life cycle, this species has become a model subject for laboratory studies on insect biochemistry (Bartu et al., 2010), endocrinology (Shaik et al., 2017) and behavioural ecology (Hotová-Svádová et al., 2010), to mention just a few recent studies.

General features of the life history of P. apterus in Central Europe are well known. The individuals usually aggregate on lime trees and the surrounding ground. The aggregations originate as a consequence of feeding on lime seeds (Tilia cordata Miller and T. platyphyllos Scopoli), but a number of other kinds of seed are also accepted (Kristenová et al., 2011). Adults disperse and spread over hundreds of metres from their place of birth (Socha \& Zemek, 2003) and may be found almost everywhere in the landscape, fields, uncultivated land and forests (Honěk, 1997; Kristenová et al., 2011). Adults overwinter following photoperiodic and temperature induction of a facultative diapause (Hodek, 1968). The dormancy is terminated in early winter before the period of deep frosts (Hodek, 1978, 1983). The period of intensive mating activity followed by reproduction starts the next spring with the onset of favourable weather. One generation and usually also a partial second generation are then produced during the growing season.

There are many studies on the mating behaviour of $P$. apterus in the laboratory. Copulation is initiated during daylight hours. Males approach females and both take a position side-by-side. The male then attaches his copulation organ to the female's genitalia, and when coupling is complete, the pair assumes the opposed position with their genitalia associated for the remainder of copulation (Žd'árek, 1970). The couples involved in copula are called "tandems". Mating activity occurs in nondormant adults reared under long-day conditions and a favourable temperature and supplied with sufficient food. It peaks 14 days after the adult moult (Socha \& Zemek, 2004a) and continues until death. However, mating propensity (activity in establishing and remaining in copula), capacity to fertilize eggs (Socha, 2008) and receptivity of females (Socha, 2004) decline with age. The insemination of females occurs within a few minutes after the start of the copulation, but males perform "postcopulatory mate guarding", i.e., maintain a tandem for a prolonged time, and thus prevent the females from mating with other partners (Schöfl \& Taborsky, 2002). The length of persistence of tandems varies with the body size of the partners. Tandems of small 
males and small females persist for the shortest time, while tandems of large females and small males persist for the longest (Honěk, 2003).

Despite intensive laboratory studies, mating behaviour under natural conditions, though very conspicuous and easy to observe, has attracted less attention. This is regrettable, since we can expect big differences between mating activity in the laboratory and under natural conditions caused by differences in age and life history of mating individuals and fundamentally different environmental conditions. A small proportion of females (1-7\%) may become inseminated before overwintering (Socha, 2010), but the bulk of overwintered females rely on copulation in spring. Copulation activity starts early in spring and continues until mid-season, when it terminates, because the overwintered parental generation dies out and adults of a new generation are dormant.

Many aspects of the spring copulation activity, which was the subject of our study, have not yet been investigated. This paper is based on four years of field observations and manipulative experiments and addresses the characteristics and course of copulation activity under natural conditions and sperm depletion in mated females. Based on laboratory results, we tested hypotheses predicting that (i) over the course of a season, mating activity will increase and fade in parallel with the ageing of overwintered individuals, and (ii) repeated mating is necessary because of sperm depletion.

\section{MATERIAL AND METHODS}

\section{Collection and maintenance of experimental insects}

Observations were made and materials collected at the base of lime trees (T. cordata) at 4 localities in western Czech Republic: Hostivice $\left(50.081^{\circ} \mathrm{N}, 14.263^{\circ} \mathrm{E}\right)$, Prague - Ruzyně $\left(50.087^{\circ} \mathrm{N}\right.$, $\left.14.307^{\circ} \mathrm{E}\right)$, Prague - Vokovice $\left(50.093^{\circ} \mathrm{N}, 14.327^{\circ} \mathrm{E}\right)$ and Prague - Dejvice $\left(50.101^{\circ} \mathrm{N}, 14.393^{\circ} \mathrm{E}\right)$. Until the experiments started within 5 days of collection, bugs were stored at $7^{\circ} \mathrm{C}$ in large plastic bottles filled with wrapped paper and sealed with nylon fabric. In the experiment, bugs were fed a surplus linden ( $T$. cordata) seeds and provided with drinking water on a moist piece of cotton. Experimental individuals and pairs were kept in cylindrical glass vials $(10 \mathrm{~cm}$ diameter, $7.5 \mathrm{~cm}$ deep) sealed with nylon fabric.

\section{Characteristics of copulation activity of caged pairs}

Frequency and length of copulation were established in an experiment carried out under natural conditions. The experimental bugs were collected at Prague - Ruzyne on 10 April 2004. On the same day, 20 heterosexual pairs were each put in a glass rearing vial and placed on half-shaded short-cut grass at the park of the Crop Research Institute $\left(50.086^{\circ} \mathrm{N}, 14.303^{\circ} \mathrm{E}\right)$. The vials were shielded from direct sunlight by a plastic sunblind with $3 \times 10 \mathrm{~mm}$ apertures that shielded about $90 \%$ of incident light. The shield was used when intensive sunshine threatened to kill the animals. The experiment continued until the death of the female; if males died before females, they were replenished from the stock of spare males kept under the same natural conditions. The tandem formation (copulation activity) was recorded for each pair during visual inspections made at $2-3 \mathrm{~h}$ intervals every day except for some weekends. During the inspections, the copulating pairs were not disturbed by any mechanical manipulation, rearing vials were opened and food or water was replenished only when couples did not establish a tandem. Every day the observations started at $\sim$ 06:00 $\mathrm{h}$ and finished at $\sim 20: 00 \mathrm{~h}$ CET. Two characteristics of copulation activity were established: (a) Frequency of tandems. Percentage of pairs involved in copulation (forming a tandem) at a particular census PT (percentage of tandems) calculated as PT $=\mathrm{NT} / \mathrm{NL} \times 100$, where NT is number of pairs involved in copulation and NL is number of pairs (females) surviving to the time of inspection. (b) Length of tandem duration. The tandem observed for a particular pair at successive inspections was assumed to persist throughout the whole period between both inspections. The length of tandem duration $\mathrm{L}$ was calculated as $\mathrm{L}=[(\mathrm{Te}+1+\mathrm{Te}$ )$/ 2]-[(\mathrm{Ts}-1+\mathrm{Ts}) / 2]$, where $\mathrm{Te}$ is the time (hour) of inspection when the tandem was observed for the last time, $\mathrm{Te}+1$ is the time of the next observation when the pair had already separated, Ts is the time of the inspection when a tandem was first observed and Ts -1 is the time of the last inspection when a tandem had not yet formed. The observations of tandems that were initiated or terminated at weekends when the experiment was unattended were excluded from the analysis. Temperature data for the period when experiment was made (Table S1) were obtained from the meteorology station of the Crop Research Institute (available at http://www.vurv.cz/meteo/).

\section{Copulation activity in wild populations}

Copulation activity was established at 4 locations where there were abundant natural populations and suitable conditions for observation, Hostivice and Prague - Dejvice in 2003, Prague Ruzyne and Prague - Vokovice in 2004, and Prague - Ruzyne in 2006. Copulation activity of the overwintered generation was recorded from start to cessation. There were 1-3 observation sessions per day, between 07:00 and 17:00 CET. At each session a minimum of 100 individuals were counted, usually $300-500$ individuals. Single individuals and individuals involved in copula (tandems) were recorded, and the percentage of individuals in copula of the total of individuals observed was calculated. In 2006, we also recorded the percentage of males among individuals not involved in copula using samples of 100-200 individuals (if available). Temperature data for the period of the observations (Table S1) were obtained from meteorology station of the Crop Research Institute.

\section{Sperm depletion}

In 2003, females were collected at Hostivice on 10 April. On the same day, 30 females were each put into a rearing vial and kept at $24^{\circ} \mathrm{C}$ under a natural photoperiod until death. For each female that survived to oviposit $(\mathrm{N}=26)$, time of deposition of successive egg batches was recorded and number of hatched (fertilised) and unhatched eggs in each batch determined. The percentage of fertilised and unfertilised eggs in successive batches was then calculated for the total population. In 2004, the females were collected at Prague - Ruzyne on 2 April (ovipositing females, $\mathrm{N}=23), 6$ May $(\mathrm{N}=25)$ and 3 June $(\mathrm{N}=24)$ and subsequently handled as in 2003 .

\section{Statistical analyses}

In addition to standard summary statistics and plots of the frequency (percentage) of copulating females, of fertilized eggs and for copulation duration, we used a formalized logistic regression approach based on GAM (Generalized Additive Model) (Wood, 2006; Hastie \& Tibshirani, 1990). In the logistic regression, we modelled semi parametrically (via penalized splines) probability of tandem formation for experimental pairs under natural conditions. The data in Figs 1 and 4 were derived (both estimated curves and pointwise $95 \%$ confidence intervals) from a single comprehensive model containing effect of both day-within-year 

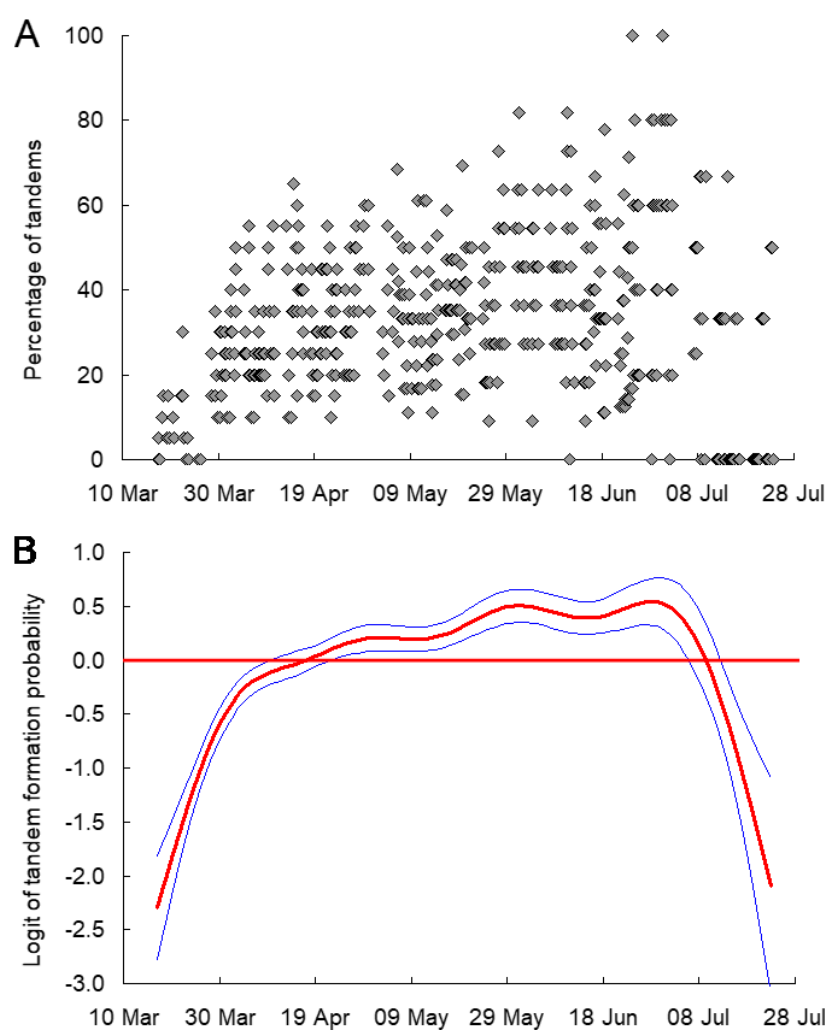

Fig. 1. Variation in frequency (percentage) of copulating females in experimental pairs recorded over the course of a season under natural conditions. A - Observation data: dots indicate percentage of copulating females observed 5-6 times daily on successive days of a season. B - Trends in seasonality of tandem formation probability (logit transformation) derived from a comprehensive logistic GAM (red line), together with pointwise 95\% confidence intervals (blue lines). Seasonal variation in probability of tandem formation is highly significant $(P<0.0001)$.

(seasonality) and hour-of the-day (intra-day periodicity). Daily periodicity component was implemented as a penalized cubic cyclic spline in order to enforce the periodic condition (and smoothness not only across hours 0 to 23 but also between 0 and 23). The GAM model from which Fig. 3 (tandem duration trends) was derived, is based on a Gaussian model with spline component in daily hours.

\section{RESULTS}

\section{Characteristics of copulation activity}

In the experiment investigating the copulation activity of isolated pairs under natural conditions, the percentage of pairs involved in copulation steeply increased until end of March, then grew very slowly until the beginning of July (average percentage of copulating pairs over this period was $37 \pm 1.1 \%$ ). Later on the percentage of copulating pairs varied greatly and the overall trend in mating activity as revealed by GAM analysis decreased until the last females died on 27 July (Fig. 1). Tandem duration varied greatly. Most tandems, $91 \%$ of the 903 cases, persisted for $\leq 1$ day (about $50 \%$ for only $\leq 0.2 \mathrm{~d}$ ), 7\% persisted for $1-2$ days, $1 \%$ for $2-3$ days and only $0.8 \%$ persisted for longer than 3 days (Fig. 2). Length of tandem duration did not reveal any obvious trend of increase or decrease during the season (Fig. 3). There was little diurnal variation in the extent of

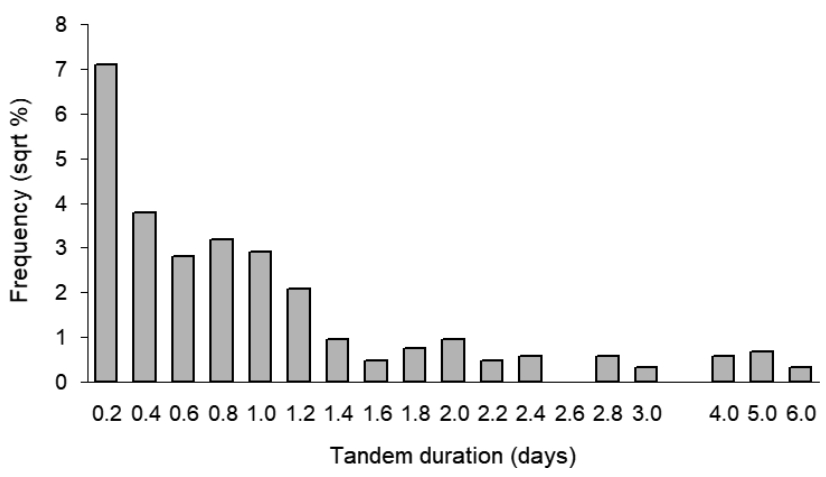

Fig. 2. Frequency of length of copulation (uninterrupted tandem duration) in experimental pairs kept under natural conditions. In order to show bars of commensurable length, the square of the percentage data is plotted on the ordinate axis.

variation in copulation activity as between 06 and $20 \mathrm{~h}$ the percentage of tandem formation varied between $0-80 \%$. GAM analysis revealed that the frequency of tandem formation was maximal between 10-18 h and decreased sharply before and after (Fig. 4).

\section{Copulation activity in wild populations}

In contrast to individuals held in heterosexual pairs, which retained full sexual activity until late June, in natu-
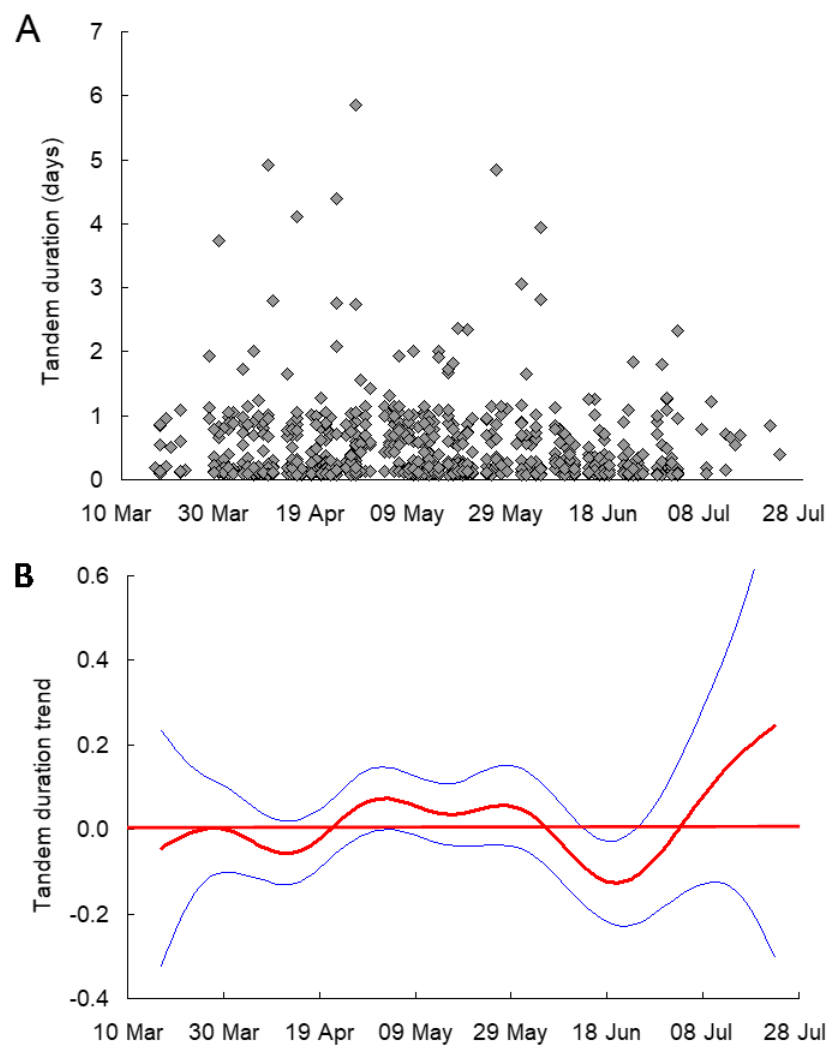

Fig. 3. Length of copulation (uninterrupted tandem duration) during the course of a season. A - Observation data: dots indicate frequency of tandem duration on successive days of a season. $B$ - Trends in seasonality in the tandem durations. The seasonal component as a difference from mean in days (red line) and its 95\% pointwise confidence limits (blue lines) were derived from a Gaussian GAM model. The seasonality of tandem duration is not significant $(P>0.05)$. 

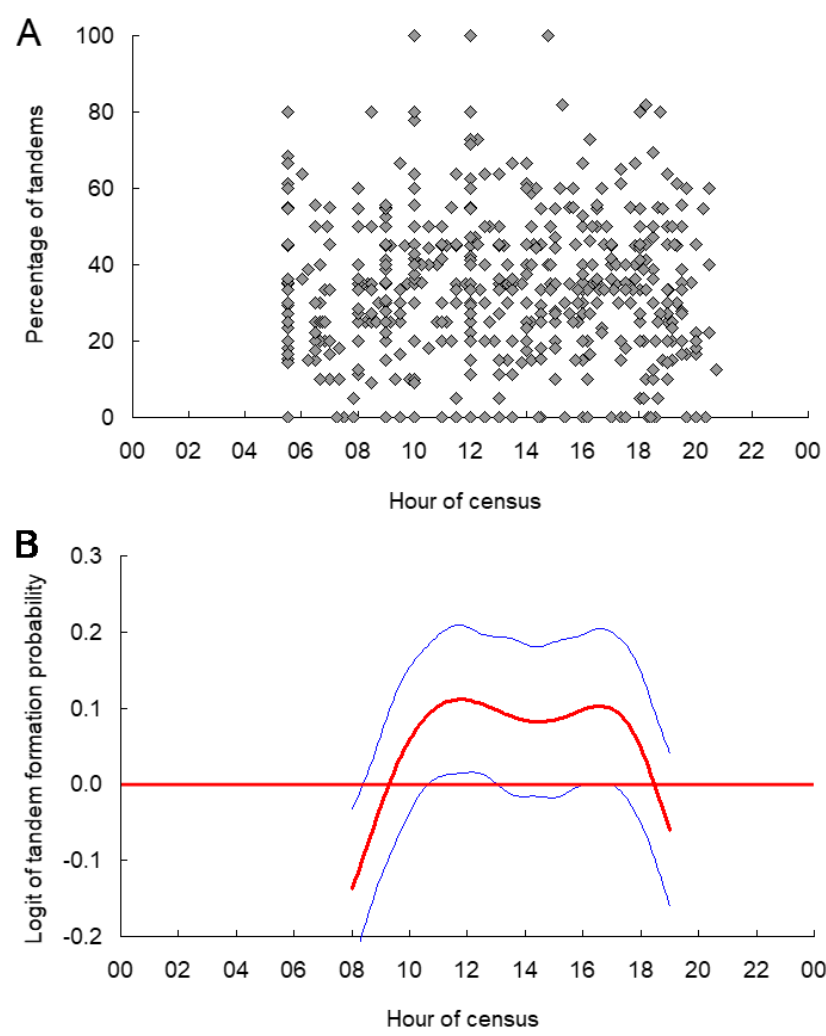

Fig. 4. Frequency of pairs in copula (tandem) in the daytime when experimental pairs were inspected under natural conditions. A Observation data: dots indicate frequency of tandems in the daytime. B - Trends in daily periodicity of tandem formation probability (logit transformation) derived from a comprehensive logistic GAM (red line), together with pointwise 95\% confidence intervals (blue lines). The daily periodicity in the tandem formation probability is highly significant $(P<0.05)$.

ral populations the percentage of individuals involved in mating varied over the course of the season. The seasonal trajectory of copulation activity was consistent across years and localities (Fig. 5). The percentage of mating individuals first steeply increased until it reached a maximum in early April, then gradually decreased towards the end of spring. Pilot observations made in 2003 and 2004 indicated that the percentage of males among individuals not involved in copula increased over the course of the season. In 2006 at Prague - Ruzyne, copulation activity peaked in April and May and then decreased until late June (Fig. 6). Among noncopulating individuals, males always prevailed over females. Before the end of May, the average percentage of males was $61 \pm 1.6 \%(\mathrm{~N}=21)$, and in June it increased to $73 \pm 2.4 \%(\mathrm{~N}=13)$. At the end of June, before the overwintered generation died, males accounted for nearly $90 \%$ of the population. The cause of this decrease in the frequency of copulation (percentage of tandems) was most likely unavailability of females.

\section{Sperm depletion}

To demonstrate whether repeated mating was necessary, we established when females suffered from sperm depletion. The females collected on 10 April 2003 (Fig. 7A) laid up to 9 batches (mean $5.2 \pm 1.87$ ). Five (19\%) females laid only fertilised eggs, while the other $22(81 \%)$ females first
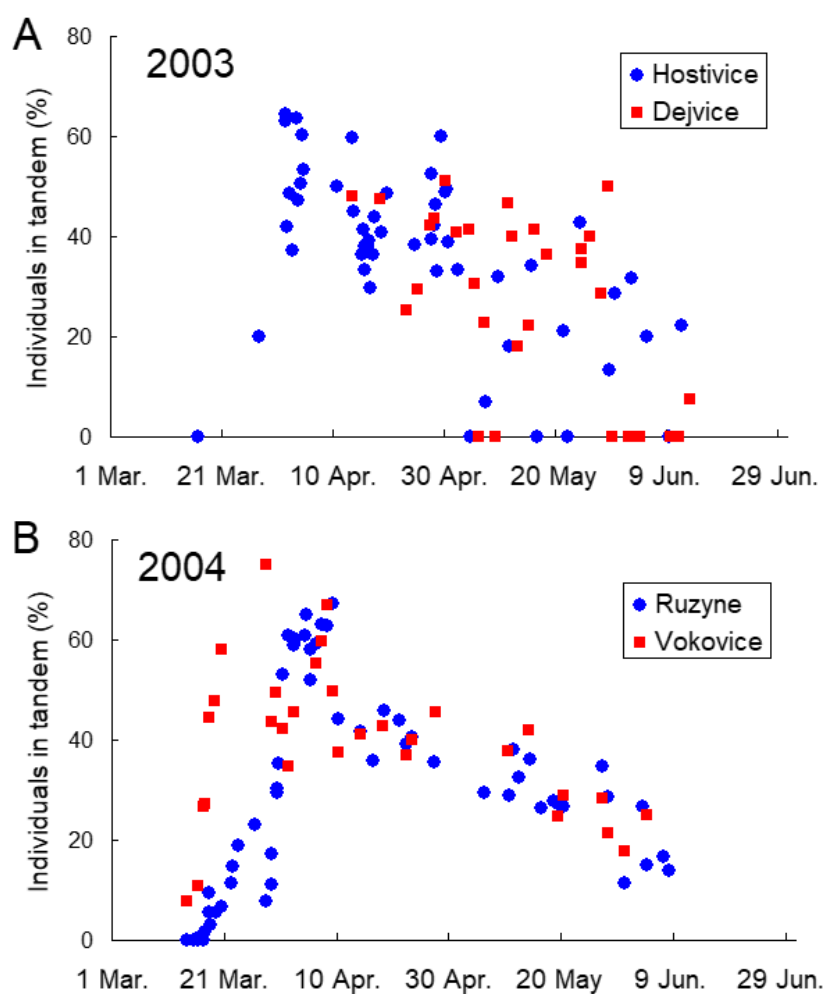

Fig. 5. Variation in frequency (percentage of total adult population) of individuals involved in mating (forming tandems) over the course of a season. A - 2003 at the localities Hostivice and Prague - Dejvice. B - 2004 at the localities Prague - Ruzyne and Prague Vokovice.

laid fertilised eggs and then unfertilised eggs. This switch occurred in the second to fifth batch (on average after laying $3.2 \pm 0.26$ batches), which was after 9-70 days (mean $23.3 \pm 2.99 \mathrm{~d}$ ) from the start of the experiment. In total $76 \%$ of the eggs were fertilised and $24 \%$ unfertilised. In females collected on 2 April 2004 (Fig. 7B), the course of oviposition was similar to that recorded in 2003. The females laid 1-9 batches and the proportion of unfertilised eggs increased starting from batch 2 to batch 7 , while batches 8 and 9 consisted only of unfertilised eggs. In total, the females laid $86 \%$ fertilised and $14 \%$ unfertilised eggs. The females sampled on 6 May 2004 (Fig. 7C) laid 1-7 batches.

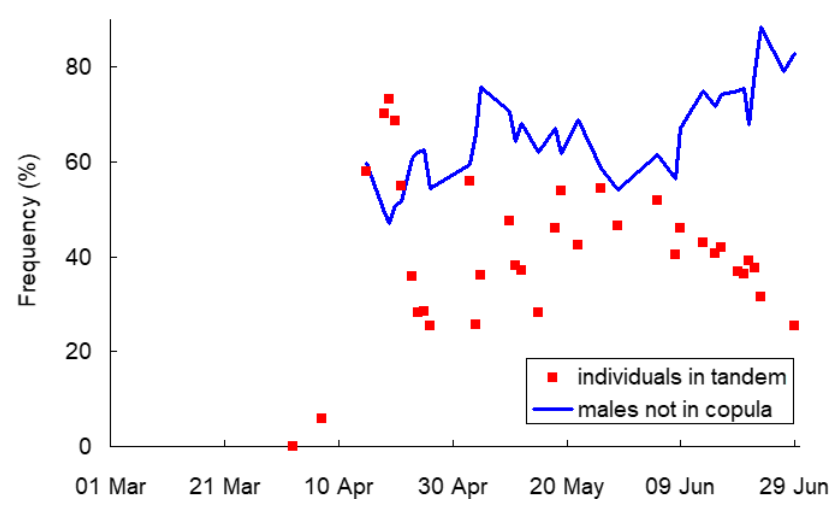

Fig. 6. Variation in frequency (percentage of total adult population) of individuals in copula (forming tandems) over the course of a season ( $\square$ ) and percentage of males among individuals not copulating $(-)$, at Prague - Ruzyne in 2006. 


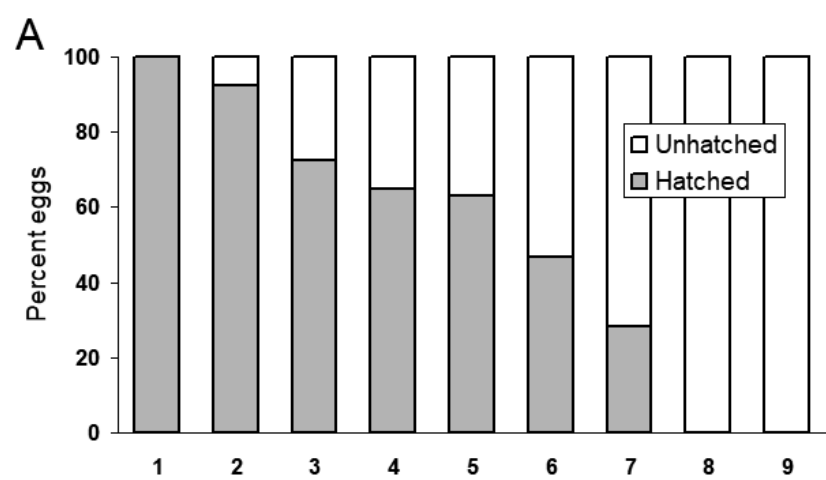

B
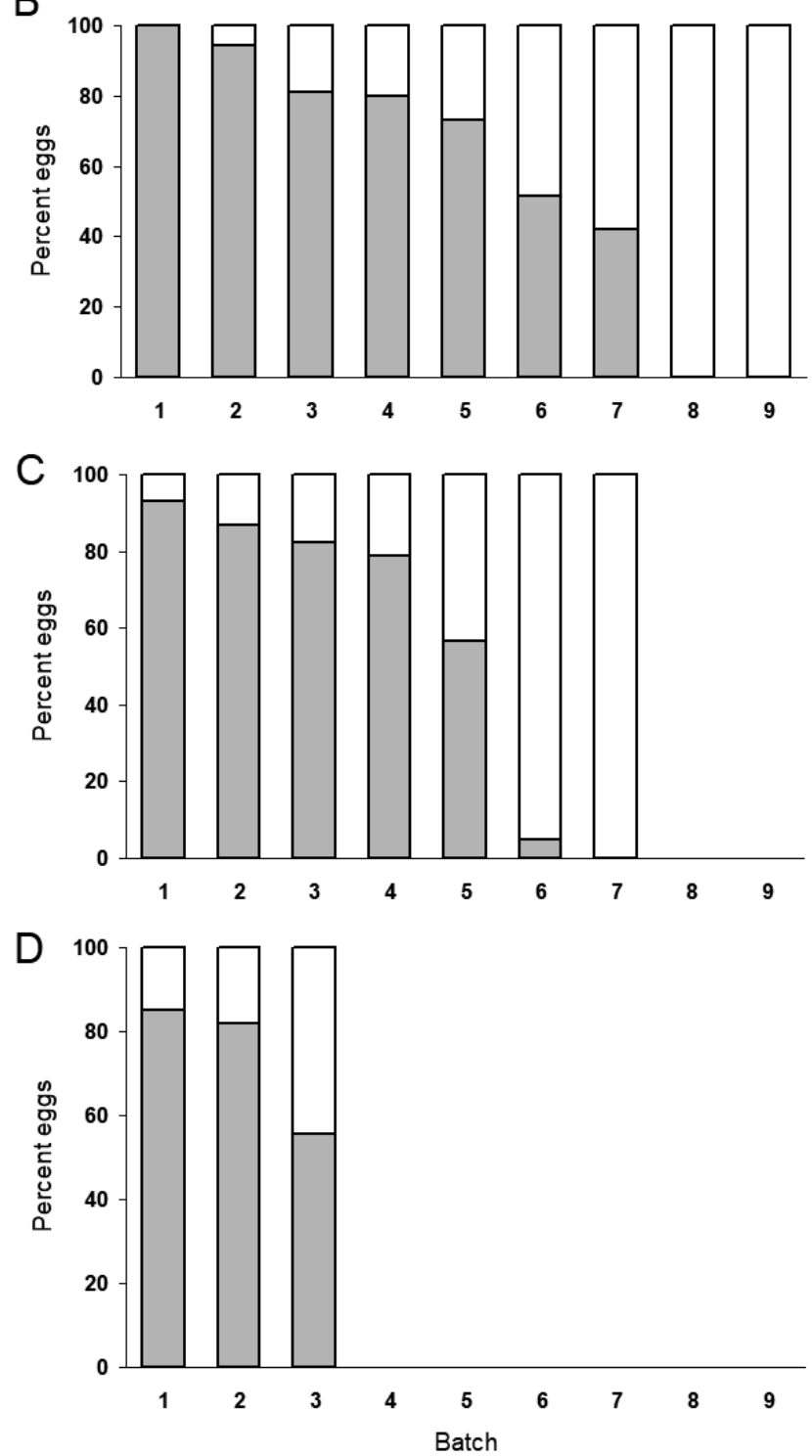

Fig. 7. Depletion of sperm in females measured in terms of the decrease in the percentage of hatched (fertilised, shaded column) and increase in the percentage of unhatched (unfertilised, open column) eggs in successive batches laid by females transferred from the open at different times during a season and kept without males until death. A - Hostivice, transferred on 10 April 2003, B - Prague - Ruzyne, transferred on 2 April 2004, C - Prague Ruzyne, transferred on 6 May 2004. D - Prague - Ruzyne, transferred on 3 June 2004.
In some females, the first batch already contained a fraction of unfertilised eggs. The proportion increased in later batches so that the last batch consisted of only unfertilised eggs. In total, the females laid $86 \%$ fertilised and $14 \%$ unfertilised eggs. The females sampled on 3 June 2004 (Fig. 7D) laid only 3 batches, all partly fertilised, giving a total of $81 \%$ fertilised and $19 \%$ unfertilised eggs.

\section{DISCUSSION}

The results reveal the factors and circumstances determining the frequency and timing of copulation activity in $P$. apterus under natural conditions and point to differences from laboratory results.

There was an important difference between mating activity in randomly interbreeding wild populations and in experiments where individual males and females were confined together. In natural populations, there was a marked increase in copulation activity in early spring, followed by a steep decrease later in the season. This course of events observed in natural populations is apparently consistent with hypothesis (i), which predicts an increase and then a decrease in copulation activity with advancing age of adults. However, our results show another factor contributing to the seasonal change in mating frequency. The male/ female ratio at the end of the breeding period indicates a scarcity of females then, which is likely to have contributed to the decreased percentage of individuals involved in tandems. Greater longevity of males compared to females, demonstrated in earlier experiments under natural conditions (Honěk, 1986), is likely to contribute to the variation in mating activity in natural populations of $P$. apterus. Seasonal variation in the length of mate guarding (duration of tandem) also might contribute to seasonal trends in mating frequency. In natural populations where mate selection occurs (in contrast to individuals kept in pairs and deprived of a choice of a mate), the duration of tandems in early spring may be prolonged, because for a male it pays to guard a young female who is likely to produce abundant offspring. In contrast, in late spring, investment in long tandem duration does not pay off because the male could be guarding an old female whose reproductive capacity is exhausted (see Fig. 7). If the length of copulation in early spring is longer than in later periods, a greater proportion of individuals in the population are involved in copulation. However, no seasonal variation in length of copulation was recorded for heterosexual pairs reared under natural conditions. Tandem duration throughout spring was similar, mostly short. The results are consistent with laboratory experiments where copulations at $26^{\circ} \mathrm{C}$ and under a longday photoperiod started 2 days after the adult moult and then continued from the seventh day with a high frequency (Socha \& Zemek, 2004a). Duration of tandems was mostly short (mean 0.05 d, maximum 0.96 d) (Socha \& Zemek, 2004b).

In animals reared in heterosexual pairs under natural conditions, there was no dramatic decrease in percentage of copulating individuals at the end of spring. This contradicts the prediction of hypothesis (i). Fluctuating nat- 
ural temperatures, which enhance the number of batches and fecundity of females (Honěk, 1986), may contribute to explaining the difference between laboratory and field results. In isolated pairs, the permanent availability of a long-lived sexual partner and/or the permanent presence of the same partner might decrease seasonal fluctuations in sexual appetite. This tentative explanation points to the need for further research on the different effects of constant laboratory and fluctuating natural conditions on P. apterus ecophysiology.

Rapid depletion of sperm in females that are prevented from remating, is consistent with the prediction of hypothesis (ii) and a strong reason for repeated copulations. A female's interest is in replenishing sperm in order to produce the maximum number of fertilised eggs. Repeated copulation thus increases progeny numbers, despite its negative effects on female longevity (Blazkova et al., 2011). The male's interest is in attempting to replace the sperm of its rivals and produce more of its own offspring. Frequent copulation is thus in the interest of both sexes and is apparently encoded in their behavioural patterns. Consequently, copulations were frequent even in isolated couples where there was no competition for and no choice of a mate.

The variation between natural and laboratory results points to the fact that copulation behaviour under natural conditions is in several aspects different from that reported in the extensive laboratory studies. An unexpected result is the low variation in mating activity observed in pairs kept under natural conditions. This contrasts with data recorded in the laboratory, where there is a diurnal variation in movement with maxima at midday and in the evening (Maxová et al., 2001), and a maximum in copulation activity in the evening (Socha \& Zemek, 2004a).

Also, differences in mating behaviour of brachypterous and macropterous individuals established in the laboratory, such as by Socha \& Zemek (2004a, b), may be different under natural conditions. This is because copulations occur after overwintering, when typical characteristics of macropterous morphs are lost (wing membrane ablated, flight muscles histolysed).

To our knowledge, there is no similar study of the lifelong course of the copulation behaviour of an heteropteran species. The reason is mainly that $P$. apterus is well suited for study under natural conditions, because of its overt life, marked copulation activity and site fidelity determined by an inability to fly. Other taxa whose way of life make it easy to observe their copulation activity under natural conditions, e.g. Gerridae (Jablonski \& Vepsaläinen, 1995), do not enable lifelong studies because of migration between sites. The characteristics of the way of life of $P$. apterus make this species particularly suitable for further studies on the differences in copulation behaviour under laboratory and natural conditions.

ACKNOWLEDGEMENTS. The work was supported by institutional support RO0418 of the Ministry of Agriculture of the Czech Republic. We thank L. Kreslová, H. Uhlířová and J. Kohoutová for excellent technical assistance.

\section{REFERENCES}

Bartů I., TomČala A., Socha R., Šmek P. \& Kodrík D. 2010: Analysis of the lipids mobilized by adipokinetic hormones in the firebug Pyrrhocoris apterus (Heteroptera: Pyrrhocoridae). - Eur. J. Entomol. 107: 509-520.

Blazkova H., Provaznik J. \& Hodkova M. 2011: Novel roles for the corpus allatum hormone in the cost of sexual interactions in the linden bug Pyrrhocoris apterus. - J. Insect Physiol. 57: 529-535.

Hastie T.J. \& Tibshirani R.J. 1990: Generalized Additive Models. Chapman \& Hall, London, $\mathrm{xv}+335 \mathrm{pp}$.

Hodek I. 1968: Diapause in females of Pyrrhocoris apterus L. (Heteroptera). - Acta Entomol. Bohemoslov. 65: 422-435.

HodeK I. 1978: Role of temperature in diapause of Pyrrhocoris apterus (Heteroptera). — Vest. Cs. Spol. Zool. 42: 172-187.

HodeK I. 1983: Role of environmental and endogenous mechanisms in the seasonality of reproduction in insects diapausing as adults. In Brown V.K. \& Hodek I. (eds): Diapause and Life Cycle Strategies in Insects. Dr W. Junk, The Hague, pp. 9-33.

HoNĚK A. 1986: Enhancement of fecundity in Pyrrhocoris apterus under alternating natural conditions (Heteroptera, Pyrrhocoridae). - Acta Entomol. Bohemoslov. 83: 411-417.

HoNĚK A. 1997: The effect of plant cover and weather on the activity of ground surface arthropods in a fallow field. - Biol. Agric. Hortic. 15: 203-210.

HonĚK A. 2003: Body size and mating success in Pyrrhocoris apterus (Heteroptera). — Eur. J. Entomol. 100: 55-60.

Hotová-Svádová K., Exnerová A., KopečKová M. \& Štys P. 2010: Predator dependent mimetic complexes: Do passerine birds avoid Central European red-and-black Heteroptera? Eur. J. Entomol. 107: 349-355.

JablonsKi P. \& VePSAläInen K. 1995: Conflict between sexes in the water strider Gerris lacustris: a test of two hypotheses for male guarding behavior. - Behav. Ecol. 6: 388-392.

KristenovÁ M., Exnerová A. \& ŠTys P. 2011: Seed preferences of Pyrrhocoris apterus (Heteroptera: Pyrrhocoridae): Are there specialized trophic populations? - Eur. J. Entomol. 108: 581586.

Maxová A., Kodrík D., Zemek R. \& Socha R. 2001: Diel changes in adipokinetic and walking activity of Pyrrhocoris apterus (Heteroptera) in relation to physiological status and wing dimorphism. - Eur. J. Entomol. 98: 433-438.

SCHÖFL G. \& TABORSKY M. 2002: Prolonged tandem formation in firebugs (Pyrrhocoris apterus) serves mate-guarding. Behav. Ecol. Sociobiol. 52: 426-433.

SHAik H.A., Mishra A. \& Kodrík D. 2017: Beneficial effect of adipokinetic hormone on neuromuscular paralysis in insect body elicited by braconid wasp venom. - Comp. Biochem. Physiol. (C) 196: 11-18.

Socha R. 1993: Pyrrhocoris apterus (Heteroptera) - an experimental model species: a review. - Eur. J. Entomol. 90: 241286.

Socha R. 2004: Decreased mating propensity of macropterous morph in a flightless wing-polymorphic insect, Pyrrhocoris apterus (L.) (Heteroptera). — Eur. J. Entomol. 101: 539-545.

SocHA R. 2008: Wing morph- and age-related differences in fertilization success of adult males of a flightless bug, Pyrrhocoris apterus (Heteroptera: Pyrrhocoridae). - Eur. J. Entomol. 105: 93-98.

SосHA R. 2010: Pre-diapause mating and overwintering of fertilized adult females: new aspects of the life cycle of the wing-polymorphic bug Pyrrhocoris apterus (Heteroptera: Pyrrhocoridae). — Eur. J. Entomol. 107: 521-525. 
Socha R. \& ZEMEK R. 2003: Wing morph-related differences in the walking pattern and dispersal in a flightless bug, Pyrrhocoris apterus (Heteroptera). - Oikos 100: 35-42.

Socha R. \& ZEMEK R. 2004a: Wing morph-related differences in the pattern of mating activity in a flightless bug, Pyrrhocoris apterus (L.) (Heteroptera). - Invertebr. Reprod. Dev. 46: $11-18$.

Socha R. \& Zemer R. 2004b: Mating behaviour and wing morphrelated differences in the sexual activity of a flightless bug, Pyrrhocoris apterus (L.) (Heteroptera). - Ethol. Ecol. Evol. 16: $217-229$.

Wood S. 2006: Generalized Additive Models: An Introduction with R. CRC Press, Boca Raton, FL, 476 pp.

ŽD́ÁREK J. 1970: Mating behaviour in the bug, Pyrrhocoris apterus L. (Heteroptera): ontogeny and its environmental control. -Behaviour 37: 253-268.

Received February 28, 2019; revised and accepted May 9, 2019 Published online June 14, 2019
Table S1. Mean ( \pm SE) and range of minimum ( $T$ min) and maximum (T max) air temperatures recorded at ground surface in March to June, in three years when the copulation activity in wild populations and in pairs caged under natural conditions were observed.

\begin{tabular}{ccrcrrr}
\hline & & \multicolumn{2}{c}{$\mathrm{T} \min \left({ }^{\circ} \mathrm{C}\right)$} & & \multicolumn{2}{c}{$\mathrm{T} \mathrm{max}\left({ }^{\circ} \mathrm{C}\right)$} \\
\cline { 2 - 4 } \cline { 5 - 6 } 2003 & March & $-1.3 \pm 0.50$ & $-7.4-4.5$ & & $11.5 \pm 1.06$ & $2.4-20.6$ \\
& April & $0.4 \pm 0.83$ & $-8.1-8.0$ & & $16.3 \pm 1.32$ & $1.4-27.4$ \\
& May & $8.5 \pm 0.62$ & $1.1-13.8$ & & $24.6 \pm 0.80$ & $16.3-34.3$ \\
& June & $12.4 \pm 0.45$ & $6.7-16.5$ & & $30.4 \pm 0.71$ & $21.7-36.7$ \\
2004 & March & $-1.0 \pm 0.65$ & $-8.8-7.1$ & & $8.7 \pm 1.28$ & $-0.4-23.8$ \\
& April & $3.1 \pm 0.56$ & $-2.7-10.1$ & & $18.3 \pm 0.88$ & $12.0-28.2$ \\
& May & $6.5 \pm 0.38$ & $1.8-10.6$ & & $21.6 \pm 0.94$ & $11.2-31.2$ \\
& June & $11.2 \pm 0.31$ & $7.5-15.5$ & & $25.2 \pm 0.78$ & $16.0-33.4$ \\
2006 & March & $-1.6 \pm 0.68$ & $-6.9-7.7$ & & $6.4 \pm 0.97$ & $0.0-23.6$ \\
& April & $3.8 \pm 0.66$ & $-3.1-11.9$ & & $17.6 \pm 1.01$ & $6.5-26.4$ \\
& May & $7.7 \pm 0.41$ & $3.0-12.1$ & & $22.5 \pm 0.70$ & $13.1-29.8$ \\
& June & $11.5 \pm 0.88$ & $3.1-17.9$ & & $27.2 \pm 1.29$ & $14.2-35.6$ \\
\hline
\end{tabular}

